\title{
Tensiones entre derechos de las mujeres y protección de la niñez
}

\author{
Valeria LLobet ${ }^{1}$ (iD) 0000-0003-0673-8260 \\ 'Universidad Nacional de San Martín, Centro de Estudios Desigualdades \\ Sujetos e Instituciones, San Martín, B.A., Argentina. \\ B1650-generoinfanciajuventud@unsam.edu.ar
}

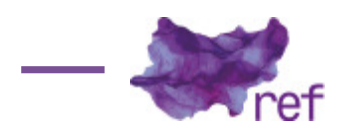

\begin{abstract}
Resumen: A partir de leer el desarrollo de la protección de la infancia en clave feminista, este artículo busca historizar algunos debates contemporáneos que hacen de los derechos de la niñez uno de los instrumentos privilegiados para disputar las batallas por el control de los cuerpos y de la sexualidad de las mujeres en Argentina. Para ello, analizo la inscripción de la protección de la infancia en tres contextos (la emergencia del estado social argentino, los debates panamericanos sobre la protección de la niñez, y el contexto global de surgimiento de los derechos de la niñez), y a la luz de dos debates actuales, el embarazo forzado de niñas y la adopción por matrimonios igualitarios.
\end{abstract}

Palabras clave: derechos de la niñez, demandas de las mujeres, movimientos de mujeres, políticas de familia.

Tensões entre os direitos das mulheres e a proteção da infância

Resumo: Partindo da uma leitura feminista do desenvolvimento da proteção da infância, o presente artigo busca proporcionar a historização dos debates contemporâneos que fazem dos direitos das crianças um dos instrumentos privilegiados para disputar as batalhas pelo controle dos corpos e da sexualidade das mulheres na Argentina. Para isto, analiso a inscrição da proteção da infância em três contextos (a emergência do estado social argentino, os debates pan-americanos sobre a proteção da infância, e o contexto global de emergência dos direitos da criança) e à luz de dois debates atuais, a gravidez forçada de meninas e a adoção por parte de casais homossexuais.

Palavras-chove: direitos da criança; demandas das mulheres; movimentos de mulheres; políticas da família.

Tensions between women's rights and child protection

Abstract: This article reads the development of child protection from a feminist point of view, seeking to historicize the current debates and struggles in Argentina that utilize children's rights as privileged instruments for the battle on the control of women's bodies and sexualities. For this purpose, I analyze the inscription of child protection in three contexts (the emergency of social state in Argentina, the PanAmerican debates on child protection, and the global context of children's rights) and through the prism of two current debates: forced child pregnancy and adoption in same-sex marriages. Keywords: Children's Rights; Women's Demands; Women's Movements; Family Policy.

\section{Introducción}

El reciente contexto de disputas en torno a los derechos sexuales y reproductivos y la educación sexual en Argentina ( $y$ en América Latina en general), movilizó retóricas en torno a los derechos de niños y niñas, tanto en sentido figurado como apelando a definiciones normativas e instrumentos de derechos humanos. Fue así posible la conformación de un frente discursivo (Claudia FONSECA; Andrea CARDARELLO, 2005) en el que actores transnacionales, ONGs, iglesias, actores estatales y medios de comunicación, convergieron en un proceso de reconstrucción de sentidos a partir de acuerdos, afinidad de intereses y procesos estratégicos de cooperación e incidencia. 
Claro, se trató de un frente discursivo que, antes que propiciar la defensa de derechos, motorizó acciones para impedir la ampliación de los mismos. En tal contexto, cobran nuevo sentido dos advertencias sobre los derechos de niños y niñas y el "superior interés del niño". Por un lado, Linda Gordon (2008) mostró cómo en Estados Unidos el desarrollo de políticas de protección a la infancia, originadas en demandas feministas, terminó siendo usado en contra de los intereses de las mujeres. A su vez, frente al desarrollo de la Convención Internacional de Derechos del Niño (CDN), autoras como Erica Burman (1996; 2008), Vanessa Pupavac (2001), Kristen Cheney (2007) y Claudia Fonseca (2004) advirtieron sobre las potenciales consecuencias negativas de la ambigüedad y del privilegio universalista de las definiciones de la CDN, esto es, su carácter especialmente apto para ser un discurso con gran polivalencia táctica (Michel FOUCAULT, 1983).

¿Qué aportaría un nuevo debate sobre los procesos de constitución del marco de derechos de la niñez? Múltiples estudios han ahondado en la historia internacional y local del proceso de institucionalización de los derechos, de su papel en la emergencia del Estado Social a inicios del siglo XX y de su relevancia en el diálogo panamericano de la primera mitad del siglo pasado (Juan SURIANO, 2000; Iskra PAVEZ, 2012; Francisco PILOTI, 1999; Donna GUY, 1998; Estela SCHEINVAR, 2010; Agustín BARNA, 2012; Julieta GRINBERG, 2013; Carla VILLALTA, 2010; FONSECA, 2004). Se ha avanzado también en considerar cómo la producción de "niños" como sujetos de derechos constituyó un largo proceso caracterizado por la construcción y reconstrucción de autoridades legítimas y modos específicos de gobierno, regulación y protección (Patrice SCHUCH, 2009; 2013; VILLALTA, 2005; 2010; Valeria LLOBET, 2009; Gabriela MAGISTRIS, 2012; Laura SANTILLÁN, 2011). Asimismo, se ha señalado la progresiva individualización de los marcos de derechos en el contexto neoliberal (GUY, 1998 FONSECA, 2004). Partiendo de estos amplios y ricos desarrollos, en este texto quiero enfocarme en las interacciones entre derechos de las mujeres y derechos de niños y niñas, desde un punto de vista que enfatice los diversos sentidos movilizados. Así, el foco está en la historicidad y las disputas por la definición de los derechos, y las formas de apropiación de la ley por parte de las y los sujetos y grupos, los modos de imprimir sus propios valores a las estructuras legales existentes (FONSECA, 2011) y las luchas en las que los derechos son una narrativa privilegiada (Elizabeth JELIN, 2011). Con ello, espero aportar a la historización de los debates que hoy hacen de los derechos de los niños unos instrumentos privilegiados para disputar las batallas por el control de los cuerpos y la sexualidad de las mujeres.

Para ello, el texto aborda en primer lugar, el lugar de los derechos de la niñez en relación con la regulación de las relaciones de género y la familia. En segundo lugar, abordaré una revisión de los estudios que han trabajado la interacción entre las demandas del movimiento feminista, el surgimiento del Estado Social y el movimiento panamericano de derechos del niño. En tercer lugar, revisaré la emergencia de los derechos de los niños en el ámbito global, para luego considerar de manera específica cómo los argumentos de derechos de la niñez han sido utilizados alrededor de dos cuestiones: la oposición al matrimonio igualitario y la oposición a la interrupción legal del embarazo.

\section{La definición de los derechos de la niñez y la regulación de la familia y la maternidad}

La representación de la infancia como el futuro de las naciones, constituyó uno de los pilares fundamentales de la "modernización" de América Latina en general, y de Argentina en particular. Así, muchos estudios analizan las ansiedades y el pánico moral sobre el desarrollo y el bienestar de la infancia que dominó la escena política desde el último cuarto del siglo XIX, y que dieron forma a las incipientes instituciones y políticas de protección a la infancia que se modelaron a inicios del siglo XX. La protección de la niñez emergió al calor de la transformación de su valor social y de los procesos demográficos y sociales que mutaron las formas dominantes de organización familiar.

Al emerger, el campo de la protección de la niñez se convirtió en uno de los principales dispositivos de regulación de la familia y las relaciones de género. De hecho, el propio concepto de bienestar infantil emergió de una complicada y conflictiva relación entre el estado y la ciudadanía, y el sistema de protección a la infancia arrastra consigo los significados culturales y legales de la familia, el género y la niñez. Las primeras políticas de protección a la infancia, desde finales del siglo XIX, combinaron objetivos moralizadores y civilizatorios en el desarrollo de nuevas formas de regulación de la vida y organización familiares y contribuyeron a expandir este ideal como norma social. Ello se conjugó con la progresiva emergencia de lo social (Jacques DONZELOT, 1980) a la vez que la consolidación de campos profesionales y la institucionalización de agencias públicas en lo que se puede conceptualizar como la producción de definiciones oficiales de familia, o, en otras palabras, la producción de una moral pública de la vida familiar (Rémi LENOIR, 1996).

Esta moralización y nuclearización de la familia en el marco de las políticas de protección social ha sido amplia y correctamente analizada como una forma de reorganización de la reproducción social que definió la maternidad, y amplió los controles sobre el cuerpo y la sexualidad 
de las mujeres, y sobre niños y niñas. Protección de la infancia y regulación de la familia y la maternidad han ido así de la mano, en particular a partir del establecimiento de normas jurídicas y legales que establecieron diferencias entre distintos tipos de familia y de filiación, a la vez que redefinieron las obligaciones y derechos maternos y paternos, y las condiciones de ejercicio de la mater-paternidad.

Diversos estudios históricos y antropológicos han señalado que a finales del siglo XIX la sanción de los Códigos Civiles "modernos" en América Latina, iniciando por Chile, y la sanción de leyes de modificación de la patria potestad, rigidizaron la relación de los nacientes estados con las familias (GUY, 1994; Nara MILANICH, 2001). En efecto, el Código Civil argentino adoptado en 1872, definió como familia legalmente constituida aquella conformada mediante matrimonio religioso católico y dominada por los varones, a la vez que no otorgaba a las madres ningún derecho sobre sus hijos, exceptuando que fueran viudas. ' Este proceso legislativo "modernizador" sancionó como legítimo y legal un modelo familiar propio de las capas medias y altas de la población (familias conyugales, convivientes en hogares unifamiliares vinculados por lazos biológicos y a la vez jurídico-legales) esto es, un tipo de organización familiar demográficamente minoritaria (MILANICH, 2001; José MORENO, 2004). Para varios autores, la distancia entre el tipo de prácticas familiares de la mayoría de la población y las nuevas normas jurídicas contribuyó al reforzamiento de jerarquías sociales alrededor de la primacía de la familia conyugal (MILANICH, 2001 ; FONSECA, 2002; Adriana VIANNA, 2005).

Pero a la vez, estos procesos históricos se constituyeron en fértiles escenarios de disputa política en los que las mujeres lograron construir espacios de participación y a la vez, colocar demandas de ampliación de derechos. Dos arenas fueron centrales. Una de ellas fue el proceso de construcción y consolidación de los estados-nación, en particular, la emergencia de diferentes formas de Estado Social. La segunda fue el ámbito internacional, en especial los Congresos Panamericanos. En ambos escenarios, distintos colectivos de mujeres se incorporaron al debate político desde el reclamo de la legitimidad que les otorgaba la controversia en curso, y el análisis de su papel permite complejizar la relación entre género e infancia en la consolidación de las arquitecturas del bienestar y la institucionalización de un enfoque de derechos.

\section{Las organizaciones de mujeres y la protección de los niños}

En los ámbitos nacionales en las Américas, la capacidad de incidencia de las organizaciones de mujeres con fines de caridad y filantropía se vinculó con la definición de las funciones del naciente estado social (SURIANO, 2000) y las transformaciones normativas que incidían en la forma de organización familiar. Para el caso de Argentina, varios estudios señalan que desde finales del siglo XIX, dos conjuntos de organizaciones de mujeres fueron centrales en la definición de los contornos de la protección estatal hacia las familias y niños de sectores populares. Por un lado, las matronas de la élite y de los sectores medios en ascenso, tanto porteños como del interior, actuando a través de organizaciones caritativas de matriz religiosa. Por otro, las feministas organizadas en agrupaciones como la Liga por los Derechos de la Mujer y el Niño, o a partir de su posición social como universitarias. En ambos casos, a la vez que las alianzas, conflictos y disputas entre las organizaciones de mujeres y otros actores contribuyeron a definir la asistencia social y las competencias estatales en la "cuestión social", constituyeron también un lugar privilegiado para la inclusión política de las mujeres en el espacio público (Valeria PITA, 2009; Yolanda ERASO, 2009; GUY, 2011 ; SURIANO, 2000).

El debate por la asistencia a niños y mujeres desamparados constituyó un escenario para la actuación de las mujeres en la arena política, y propició su legitimación como voces válidas en las disputas por la construcción del estado social. La función de la "cara maternal" del Estado y el "reservorio moral" de la sociedad, atribuidas a las organizaciones de beneficencia comandadas por mujeres, configuró una plataforma de relevancia para su agencia política. A la vez, en las disputas por la definición y el desempeño de estas funciones morales y sociales del estado, no encontramos sólo las marcas de las mujeres de los sectores dominantes. Los usos de la beneficencia pueden verse como una práctica interpersonal de reciprocidad generadora de relaciones desiguales y jerárquicas, pero que también fueron instrumentalizadas por los dos extremos de la relación: proveedores/as y receptores/as (Beatriz MOREYRA, 2009). Donna Guy y Yolanda de Paz Trueba, por ejemplo, auscultaron los límites que encontraron los controles que se pretendían instalar, límites manifiestos en las fugas de niños/as "colocados/as" en casas de familias por las instituciones de beneficencia y los defensores de menores, asiì como los reclamos de reintegro de sus madres (GUY, 1994; DE PAZ TRUEBA, 2009). Cecilia Tossounian (2013) por su parte, mostró como las Damas Vicentinas, al lidiar con las "necesidades morales y materiales" de las jóvenes de sectores populares,

\footnotetext{
1 En Brasil, Claudia Fonseca rastreó los modos en que las mujeres de sectores populares trataban de sortear la normativa o al menos imprimir sus propios valores a las estructuras legales. Como los padres, incluso de hijos ilegítimos, tenían prioridad de derechos, las mujeres frecuentemente omitían el nombre de su compañero en el certificado de nacimiento de sus hijos, para garantizar su autoridad.
} 
articulaban perspectivas conservadoras con formas pragmáticas de resolución de los problemas, aceptando la autonomía económica como un resguardo moral.

Así, la emergencia de la protección de la infancia como problema social fue contemporáneo de la formalización e institucionalización de las relaciones familiares, de la redefinición del papel de las madres en el marco de la crianza de los hijos, y de la emergencia del Estado social moderno, con sus dispositivos jurídico-legales e institucionales. En este marco, relaciones de género y estereotipos sobre la maternidad convergieron en construir unas bases muy firmes para determinadas formas de comprensión de las necesidades de la niñez que se vinculaban con la regulación de los comportamientos públicos y privados de mujeres y niños. A la vez, constituyó una base de inclusión política -y paulatinamente profesional- de las mujeres de sectores medios y altos.

\section{Protección de niños/as y movimientos de mujeres en el ámbito panamericano.}

Si la protección de la niñez emergió como consecuencia de procesos modernizadores y del avance del capitalismo, su implantación en las sociedades latinoamericanas, incluyó también elementos conservadores y tradicionalistas. En el ámbito panamericano las principales voces para colocar la protección de los niños como tema relevante fueron las de las feministas socialistas (GUY, 1998). Ahora bien, este activismo también se basaba en el maternalismo (Marcela NARI, 2000) como estrategia y narrativa central. Esto es, la presunción de que las demandas ciudadanas de las mujeres derivaban de su papel como madres, y que la protección de los hijos era una vía de protección a las mujeres obreras. Este proceso de convergencia compleja entre las demandas por el acceso a derechos políticos y sociales por parte de grupos de mujeres activistas y las demandas de protección a niños/as, tuvo diferentes escenarios y clivajes.

Los Congresos Panamericanos, desde 1916 hasta finales de la Segunda Guerra Mundial, se convirtieron en un escenario en el cual las feministas hicieron nacer un movimiento latinoamericano de protección de los derechos de niños/as que interpelaba a los estados para el desarrollo de acciones que protegieran a la familia obrera y sus hijos. Desde inicios del siglo XX distintos grupos convergieron en estos congresos para promover la protección de la niñez. Uno de los ejes de disputa política lo constituyó la definición de la protección como responsabilidad del Estado (como reclamaban las feministas y fue institucionalizado en países como Uruguay, por ejemplo) o si era adecuadamente satisfecha por las organizaciones de beneficencia, esa "cara moral del Estado" (como querían las matronas y muchos intelectuales y profesionales varones que componían la mayoría de las delegaciones), o, finalmente, si debía ser resuelto en el seno de las familias mediante apoyos profesionales, como era planteado por las trabajadoras sociales estadounidenses (GUY, 1998). Para Guy, la presencia de las trabajadoras sociales feministas evitó el liderazgo indisputado de ideólogos eugenésicos: "sin las feministas maternalistas disputando sus visiones sobre los temas de la protección a la infancia, es posible que hubieran surgido modelos de asistencia mucho más autoritarios" (1998, p. 466).

Los tipos de medidas propuestas en los ámbitos panamericanos examinaban los "determinantes sociales" de problemas como la mortalidad infantil, el trabajo infantil, el abandono, etc., colocando un énfasis en la pobreza, la educación, las características raciales y eugenésicas, y el prohibicionismo en materia de consumo de alcohol, como era promovido por la American Temperance Society. El impulso de leyes de protección a trabajadores, la formación de clubes y cantinas para madres y niños, el desarrollo de campañas educativas, eran vistos como medidas a ser promovidas a lo largo y ancho de las Américas.

Las preocupaciones por el abuso infantil eran un fuerte subtexto de las campañas prohibicionistas y la promoción de la "Ley Seca", que veían la violencia de los varones como la causa central. Así, las demandas por la protección a los niños tenían un componente antipatriarcal, dado que pedían intervenciones que limitaran la autoridad de los padres sobre sus hijos $-y$, complementariamente, sobre sus esposas. Las narrativas se construían también sobre la base de las demandas por maternidades correctas y apropiadas, capaces de evitar la crueldad hacia los niños, y las madres eran de igual forma vistas como los medios para la protección a la niñez. Así, las trabajadoras sociales y otras filántropas reformadoras sociales movilizaban narrativas moralistas que, no obstante, buscaban limitar el poder patriarcal en el hogar, considerado cruel y abusivo. Al hacerlo, la centralidad la adquiría el niño como "víctima inocente" en desmedro de sus madres (Linda GORDON, 2008).

Hasta la emergencia de la CDN, es posible identificar tres fuerzas que ubicaban a los niños como tópicos de preocupación pública: la filantropía, la medicina y las ocupaciones alrededor de la delincuencia juvenil, en particular el derecho (Göran THERBORN, 1996). En cada caso, la definición de la protección alcanza diferentes grados de exigibilidad, y los actores encargados de su satisfacción también variaban, junto con la definición del tipo de problemas apropiado. Y de ello dependía su carácter de derecho. 
En suma, más que presuponer una relación lineal entre las formas de control, es relevante en este proceso, registrar las ambigüedades y las contradicciones en materia de protección y sus efectos sobre las dinámicas familiares, las formas de autoridad y las relaciones de género y edad. A la vez, en el ámbito panamericano, el activismo de las organizaciones de mujeres propició el surgimiento de un movimiento regional de protección a la infancia, la diseminación de saberes y el establecimiento de redes de activistas, profesionales y expertos, $y$, de manera indirecta, el surgimiento del propio organismo especializado, el Instituto Interamericano del Niño.

\section{El contexto global de debate}

De igual modo, en el ámbito europeo, los movimientos filantrópicos reclamaban que la situación de la niñez "abandonada o delincuente" fuera considerada un problema social. En tal contexto cultural e ideológico, si bien niños y niñas eran colocados en el centro de la escena, lo eran desde un punto de vista hasta cierto punto instrumental. La primera declaración de derechos, ratificada por el V Congreso General de la Sociedad de las Naciones el 28 de febrero de 1924, fue resultado del trabajo de Eglantyne Jebb y la organización fundada por ella, Save the Children (StC).

En 1959, ya en el marco de Naciones Unidas, comenzó a debatirse la ratificación de la declaración de 1923, teniendo a la vista los terribles impactos de la Segunda Guerra Mundial y de los procesos descolonizadores que le subsiguieron. El contexto de institucionalización internacional de los instrumentos de derechos humanos implicaba un avance respecto del proceso moral de décadas anteriores. Al mismo tiempo, proveía una arena política de relevancia para varias disputas.

Una contienda relevante desde el punto de vista que queremos colocar aquí tuvo lugar en las reuniones preparatorias. Las delegaciones de Israel y Polonia bregaron por tratar directamente el problema de la desigualdad de niños/as extramatrimoniales y propusieron la inclusión de un artículo que expresamente prohibiera la discriminación de la niñez en razón de su nacimiento por fuera del matrimonio (Philip VEERMAN, 1992; BARNA, 2012). La propuesta fue rechazada por el representante de Italia, que colocó además otro tema en agenda: la definición del criterio de inicio de la infancia. En aquel momento, a través del Bureau International Catholique pour l'enfance (BICE), abogó por el establecimiento de la concepción como el momento en que iniciaba la titularidad de derechos del niño. Los debates terminaron "sobre tablas": la igualación de la niñez por encima de sus condiciones de nacimiento se restringió a una mención al derecho a la igualdad "sin distinción de raza, religión o nacionalidad", y la Declaración de 1959 no mencionó la concepción como momento de inicio de la infancia (Cynthia PRICE COHEN 1997).

En 1979, en el vigésimo aniversario de la declaración, la ONU estableció el Año Internacional del Niño a iniciativa del gobierno polaco, cuya delegación propuso además un primer borrador de Convención especializada, rechazado por la Comisión de Derechos Humanos por no haber sido escrito en un lenguaje que permitiera su exigibilidad. Con ello se abrió un período de diez años de trabajo en torno a la redacción de los artículos, en el cual viejos conocidos como BICE y StC lideraron inicialmente el cabildeo de la sociedad civil internacional. Sólo hacia la mitad del proceso la labor de agencias como UNICEF cobró relevancia, instando -junto con Defensa de Niños y Niñas Internacional, DNI- a la participación de delegaciones latinoamericanas, y a la vez permitiendo mitigar algunos de los conflictos más serios del proceso.

La CDN establece que los derechos, en lugar de ser clasificados bajo la tradicional taxonomía de derechos económicos, sociales, culturales, civiles y políticos, pueden ser comprendidos como de promoción, protección y provisión. A la vez articula cuatro principios generales ${ }^{2}$ y tres protocolos facultativos. ${ }^{3}$

Varios estudios han señalado que las peculiaridades de la CDN como instrumento de derechos humanos se vinculan con el contexto político de Guerra Fría en que se debatió (Eugene VERHELLEN, 1994). Al mismo por ejemplo se debe la innovación en la clasificación, que elude la tensión política entre este y oeste expresada en la conceptualización de la injusticia (como basada principalmente en las desigualdades socioeconómicas, para el espectro socialista, o basada en los fallos de la democracia, para los países occidentales), así como la incorporación de derechos específicos vinculados con la agencia política infantil.

La relevancia del análisis del contexto histórico-político de emergencia de la CDN es clara. Se vincula con varios procesos simultáneos: el final de la guerra fría, el debate por los derechos de las mujeres en el marco de la ONU y las características del proceso de globalización. Así, en primer lugar, las disputas entre el Este comunista y el Occidente democrático/capitalista tuvieron gran relevancia en el debate y establecimiento de instrumentos de derechos humanos. En ese contexto, para algunos analistas la presentación de la delegación polaca tuvo en la mira, centralmente,

\footnotetext{
${ }^{2}$ No discriminación contra los niños, predominio del interés del niño, derecho a la vida, la sobrevivencia y el desarrollo, derecho a expresar su punto de vista en los asuntos de su incumbencia.

${ }^{3}$ Participación de niños en conflictos armados; Venta de niños, prostitución infantil y utilización de los niños en pornografía; Procedimiento de comunicaciones y denuncias sobre violaciones ante el Comité.
} 
aminorar el protagonismo internacional en la defensa de los derechos humanos que estaba adquiriendo el gobierno de Carter (PILOTI, 1999). Ello fue respondido mediante el trabajo articulado de las delegaciones "occidentales" (EE.UU., Canadá, Gran Bretaña, Francia) quienes conformaron un bloque que votó de manera conjunta prácticamente en la totalidad de los casos.

En segundo lugar, la discusión llevada adelante por las feministas desde inicios de la década de 1970, también en el ámbito de la ONU, dio como resultado el Año de la Mujer en 1975, múltiples informes sobre la situación de mujeres y niñas alrededor del mundo, y una general disposición a considerar a las minorías como requeridas de protección especial. En ese marco, y en especial luego de la Conferencia Mundial de Derechos Humanos de 1993 (Conferencia de Viena) la relación entre derechos de las mujeres y de las niñas comenzó a ser objeto de controversia. En la Conferencia de Viena se indicó expresamente que los derechos de la mujer y la niña son parte inalienable, integral e indivisible de los derechos humanos universales, declarando que la violencia por edad y por género es incompatible con la dignidad humana y debe ser erradicada. La conferencia, que propició una matriz interpretativa a los instrumentos de derechos humanos que busca hacer lugar al conflicto, la complementariedad y la simultaneidad, fue seguida por reuniones preparatorias de la Conferencia de Beijing, en las que las tensiones entre ambas agendas fueron expresadas.

Para algunas analistas, la Convención por la Eliminación de toda forma de Discriminación contra la Mujer (CEDAW) falla en incorporar provisiones referidas a las necesidades de las niñas, y en general, trata a la niñez como propiedad de las familias y no como individuos con derechos (PRICE COHEN, 1997). Así por ejemplo, Price Cohen señala que, a pesar de los intentos por establecer acuerdos entre las organizaciones promotoras de los derechos de las mujeres nucleadas en el Comité de Seguimiento de CEDAW y las organizaciones promotoras de derechos de la niñez, con motivo de la conferencia de Beijing de 1995, persistió una desconfianza hacia la CDN basada en un adultismo que no consideraba la protección de los derechos de las niñas parte de los objetivos a proteger por parte de las organizaciones de mujeres.

Desde el punto de vista de quienes propician la sinergia entre ambos instrumentos y entre las agendas de derechos de mujeres y de la niñez, la integración de la protección de derechos específicos que no estaban desagregados en otros tratados, tales como la identidad, el acogimiento familiar, la adopción, y la oposición a prácticas como la mutilación genital, permitieron avanzar en el logro de un instrumento de derechos capaz de modificar prácticas y significaciones culturales que contribuían a la persistencia de intensas desigualdades de género. A su vez, la CDN es el primer instrumento de derechos en el que se cuestiona el lenguaje sexista. En efecto, gracias a la intervención de la delegada canadiense, se modificó el registro masculino para lograr un instrumento "neutro" (PRICE COHEN, 1997). Finalmente, a pesar de la renovada presión de las organizaciones católicas y el representante del Vaticano, ahora presente en los debates, no se incorporó la definición de niño desde la concepción. Todo lo contrario, países como Francia y Canadá propiciaron una redacción que garantice que la protección de derechos de la niñez no colisionara con los derechos sexuales y reproductivos de las mujeres.

Therborn (1997), por su parte, señala que esta nueva clase de política inaugurada por el énfasis en los derechos humanos tiene algunas características principales, que se vinculan con el establecimiento de una agenda internacional que se entreteje con asuntos internos de los estados y se plantean objetivos de cambio social tanto como estatal. Este nuevo tipo de política va en desmedro del abordaje centrado en la autodeterminación y soberanía estatal para abogar por derechos universales, y se vincula con la emergencia del feminismo y los movimientos de derechos de las mujeres, los que proveyeron, para el autor, tanto el foco en los derechos humanos como el tipo de activismo orientado a la ampliación de derechos. El movimiento feminista, desde este punto de vista, aportó tanto a la visibilización de los niños, a partir del desafío de la definición de las demandas de participación pública, como a la conceptualización de la misma a partir de la deconstrucción de la familia y su individualización mediante un igualitarismo individualista que minó el colectivismo patriarcal (THERBORN, 1997).

En tal sentido, la visibilización de niños y niñas en un marco de desnaturalización de la familia patriarcal, el detalle otorgado a la discriminación y la violencia contra las niñas en la Convención sancionada en 1989, a la vez que la crítica al carácter generizado del lenguaje de los instrumentos internacionales de derechos humanos, y la apertura al debate sobre los derechos sexuales y reproductivos de las mujeres -resuelto de manera individual por cada país signatarioconvertiría a la CDN, para algunas analistas, en un logro desde un punto de vista feminista (PRICE COHEN, 1997).

En contraposición a este planteo, autoras como Burman (1996a) señalaron diversos problemas en el texto y el proceso de debate de la convención, que la harían como mínimo problemática desde el punto de vista de la transformación de las desigualdades de género. Así, un cuestionamiento sustantivo se basa en los supuestos sobre la infancia que subyacen a la Convención, marcadamente "nor-atlánticos" (Vanessa PUPAVAC, 2001). Burman (1996b; 2008) alerta respecto de los chauvinismos de género y culturales que estructuran los procesos de definición de 
qué es mejor para los niños. Según ella, el discurso universalista de derechos, con su componente moral, permite la naturalización de evaluaciones normativas respecto de cómo son los niños y cómo deben ser. Las "anomalías conceptuales" conectan así con la discusión de los modelos psicológicos de infancia, y emergen de la ambigüedad del concepto de derechos, que es visible en el conflicto entre bienestar y autodeterminación.

En tercer lugar, el proceso de debate y posterior sanción de la CDN se dio en el marco de la globalización neoliberal y ello requirió cambiar de escala para considerar en el análisis el reìgimen internacional (PUPAVAC, 2001) o la industria global (Didier REYNAERT; Maria BOUVERNE-DE BIE; Stijn VANDEVELDE, 2009) de los derechos del ninPo. Pupavac señala que éstos son concebidos sobre la base de supuestos morales universales que representan, para sus promotores, una vía de igualación entre países y de superación de las divisiones internacionales, omitiendo que la erosión de la soberanía entre países es desigual en función de esas divisiones (PUPAVAC, 2001). Adicionalmente, el proceso de debate y aprobación consensual de cada artículo, basado en un paradigma humanitarista con pretensioìn de neutralidad (Roger HART, 1997), presupone un consenso global sobre las politicas que deben implementarse para acceder al "interés superior del niño," desoyendo las prácticas y las estructuras sociales que inciden en la producción de desigualdad, y el impacto que las relaciones internacionales tienen sobre tales procesos de transformación, en un proceso que se ha denominado patologizacioìn del Sur (PUPAVAC, 2001).

En Latinoamérica la CDN se institucionalizó en el entrecruce de dos procesos históricos específicos: mediante la reforma del estado y la neoliberalización que subsiguió al Consenso de Washington, y por otro lado, mediante el activismo de actores locales vinculados con los derechos humanos, protagonistas del proceso de democratización de numerosos países de la región (GRINBERG, 2013; FONSECA; CARDARELLO, 2005). América Latina adhirió de manera masiva a los principios de la CDN, y "ya nadie discute... que la protección de la niñez debe plantearse a partir de un enfoque de ciudadanía y de protección de los derechos humanos de niños y niñas" (Mary BELOFF, 2008, p. 11). Las únicas reservas (la restricción de la aplicabilidad de un artículo) se han dado sobre la participación de niños/as en conflictos armados y la protección legal en adopción internacional (artículos 38 y 21). En cuanto a las declaraciones interpretativas, cuyo valor vinculante es menor, Argentina, Ecuador y Guatemala declararon una extensión al artiìculo 1 relativo a la Definición del Niño para incorporar "desde la concepción".

En suma, la discusión sobre los poderes en juego, sus agendas y los modos en que las mismas se expresaron, resulta central para entender las tensiones y dificultades respecto a por qué la incorporación de un lenguaje neutro desde el punto de vista de género dista de ser suficiente para interpretar los derechos de niñas y niños como precursores de los derechos de las mujeres adultas, como abogó Price Cohen. No obstante esa controversia respecto de la tensión, complementariedad o sincronicidad con los derechos de las mujeres, la CDN, con su campo de actores y debates, se ha configurado en un instrumento motorizador de transformaciones relevantes, no siempre unívocas, respecto de la democratización social. En primer lugar, el papel de las familias en la normativa pasó de ser un locus de formación de los individuos, a ser sujeto de responsabilidades. Complementariamente, la normativa establece una transformación del papel del Estado, que pasó a ser definido como promotor y responsable de la garantía de los derechos de niños y niñas. Finalmente, y de manera similar a los derechos de las mujeres, los derechos de la niñez muestran una tensión irresoluble entre la necesidad de protección y la autonomía, formalmente resuelta a través de la denominación de los niños como 'sujetos especiales de derechos', reconociendo la desigualdad legal y jurídica en la que están colocados, a partir de la óptica de la protección.

La CDN ha abierto así nuevos campos de disputa, plurales y diversos en función de las contiendas en contextos específicos, y sus sentidos y usos han sido instrumentales tanto en combates por ampliación de derechos como en búsquedas de restricción de los mismos. Se ha señalado que las visiones instrumentalistas distorsionan la realidad mediante el ocultamiento de su complejidad, al fallar en tomar en cuenta las variaciones y las "constantes" en los contextos locales (Pamela REYNOLDS; Olga NIEUWENHUYS; Karl HANSON, 2006). Así, concepciones morales sobre la infancia procuran "ganar la batalla" negando o evadiendo la conflictividad que estructura los contextos locales, e intentan propiciar imágenes del "interés del niño" como una prioridad indiscutible, aunque se trate de batallas políticas en las que alguien va a tener que ganar y alguien va a tener que perder.

La indeterminación y la consecuente polivalencia de las definiciones de "niñez", esto es, la variabilidad en las definiciones sobre quién es el sujeto a ser protegido, es una de las demostraciones más claras del carácter políticamente debatido de las definiciones operativas de la protección: las formas de concretarla, la extensión y características que tendrá, y los actores llamados a garantizarla.

Vamos a considerar dos temas específicos, la adopción y el aborto, donde el concepto "interés superior del niño" y la propia definición de "niño" muestran su permeabilidad en la disputa de proyectos contrapuestos en torno a la igualdad de género. 


\section{Sexualidades, familia y adopción}

El "Interés Superior", como dijimos, ha sido cuestionado por tratarse de un concepto abierto e indeterminado, aunque se han construido definiciones que intentan morigerar su indefinición operativa (BELOFF, 2008). Los debates sobre adopción en matrimonios igualitarios ofrecen un ejemplo cercano, en los que el "interés superior" ha sido utilizado para movilizar argumentos para limitar a parejas homosexuales la posibilidad de adoptar, o bien, discriminar a padres o madres que no tienen una orientación heterosexual en casos de custodia (Geraldina GONZÁLEZ DE LA VEGA, 2011). En algunos casos, ese "interés superior" se ha vinculado con la naturaleza bisexuada de la reproducción humana, como en el debate sobre el matrimonio igualitario en la década de 1990 en Francia, donde para algunos expertos, "tergiversar" la reproducción en un orden familiar "homosexual" iría en contra de la niñez y sus derechos (Irène THÉRY, 1998).

En el caso argentino, en ocasión de la reforma del matrimonio civil, la posibilidad de la adopción fue uno de los tópicos movilizados por los sectores conservadores para galvanizar posiciones en su favor, en un contexto cada vez más inclinado a apoyar la llamada "Ley de matrimonio igualitario", por oposición a una jerarquización de las uniones en función del sexo de los contrayentes. Diputados y senadores vinculados con sectores católicos movilizaron argumentos en contra del matrimonio igualitario debido a que el mismo incluía la posibilidad de adopción. Para ello, apelaron a temores vinculados con el abuso sexual hacia niños y niñas por parte de padres varones, un tópico usual de lo moralmente intolerable (Didier FASSIN, 2011). Por ejemplo, el entonces jefe de la bancada del PRO, Federico Pinedo, señaló en una nota del diario La Nación publicada el 5 de mayo de 2010 "desconocer los efectos en el desarrollo de los menores de edad cuando son adoptados por homosexuales." Los sectores de la sociedad civil organizados en torno a las iglesias católica y evangélica se manifestaban bajo el lema "Los chicos tenemos derecho a mamá y papá", y el entonces cardenal Bergoglio llamó a no dejar de lado los derechos de los niños, desde su punto de vista vulnerados si se aprobaba la ley.

Desde posiciones a favor de la ampliación de derechos, las respuestas mostraban la porosidad de la ley vigente y los usos prácticos que de la misma hacían las personas no contempladas expresamente debido a su orientación sexual. Así, Vilma lbarra, autora de uno de los dos proyectos de ley debatidos, señaló en una entrevista del diario Página 12 del 27 de octubre de 2009 (Horacio $\mathrm{CECH}, 2009$ ) que, debido a que la ley anterior permitía la adopción de una persona soltera, personas homosexuales ya adoptaban a niños y niñas. Más aún, señaló que la ley existente "anula los derechos del niño, porque si hay una separación solo puede reclamar alimentos a uno, y la otra parte, además, no tiene derecho al régimen de visita."

En el caso Atala Riffo e Hijas contra Chile, la Comisión Interamericana de Derechos Humanos (CIDH, 2011) sentó precedente y resolvió a favor de Karen Atala, quien mantenía una relación homosexual por la cual la justicia chilena le retiró la custodia de sus hijas. En ese caso las instancias judiciales chilenas consideraron que el contacto entre ella y sus hijas no era coincidente con el Interés Superior del Niño (GONZÁLEZ DE LA VEGA, 2011). La CIDH señaló el uso arbitrario y malicioso del principio por parte de la justicia chilena:

la decisión tuvo como sustento las propias concepciones estereotipadas de los jueces sobre la naturaleza y efectos de las relaciones entre personas del mismo sexo... la invocación de la orientación sexual de los padres no puede justificar la pérdida de la custodia".

http://www.corteidh.or.cr/docs/casos/atala/alefcom.pdf (CIDH)

En suma, sectores del poder judicial, el poder político y la iglesia han movilizado argumentos vinculados con el "interés superior" para intentar bloquear transformaciones en la organización familiar y en las jerarquías sociales basadas en el género, la identidad y orientación sexual. A su vez, la retórica de la sociedad civil conservadora pivotaba sobre la estrategia de arrogarse la voz de niños/as: el lema de campaña era enunciado en primera persona, en un deslizamiento instrumentalista que se mantendría como recurso retórico de legitimación en otras contiendas. Apelaron a formulas emotivas, imágenes estereotipadas y un discurso religioso que enfatizaba paralelismos entre la niñez y Jesús niño (BBC, 2016), esquema que se repitió a todo lo largo de Latinoamérica desde el pasado decenio. Las organizaciones LGBTQQ que militaban la aprobación de la ley, movilizaron sentidos vinculados con la naturaleza del amor como necesidad de los niños, y la igualdad de los lazos que configuraban el matrimonio: "el mismo amor, los mismos derechos".

\section{Maternidad infantil forzada y definición de "niño"}

En 2015, organizaciones promotoras de derechos humanos denunciaron al Paraguay ante la Comisión Interamericana de Derechos Humanos, debido a la situación de una niña de once años que ingresó a un hospital de Asunción con un embarazo de 21 semanas producto de haber sido violada por su padrastro. A pesar de que el aborto es legal en Paraguay ante el peligro para la vida de la mujer, y el grupo de seguimiento de la CEDAW estableció que "no proporcionar a la 
niña el aborto terapéutico de manera oportuna resulta en graves violaciones de sus derechos a la vida, a la salud y a la integridad física y mental, así como a su derecho a la educación, poniendo en peligro sus oportunidades socio-económicas", las autoridades paraguayas se negaron a reconocer los riesgos a los que exponían a la niña. La Comisión Interamericana se expresó en la misma dirección que el Comité CEDAW y elevó el caso a la Corte Interamericana, vinculando el caso con la normativa de prevención de la tortura y el trato degradante, sentando así un precedente en relación con el embarazo forzado en la niñez. ${ }^{4}$

Esta situación es repetida a lo largo de América Latina, como evidenció el informe del Comité de América Latina y el Caribe para la Defensa de los Derechos de la Mujer (CLADEM), organización que en 2016 inició una visibilización regional del tema, señalando que en todo el continente, con la excepción de El Salvador, se desconocen las cifras de embarazo de niñas menores de 15 años debido a que sólo se registran los partos. Para el caso argentino, el ex Ministerio de Salud evidenció que en 2015 nacieron 2.787 niños de niñas de 10 a 14 años, las adolescentes de entre 15 y 19 años dieron a luz a otros 108.912 bebés, y 2 de cada 3 (67\%) reportaron al momento del posparto que ese embarazo no había sido intencional.

El embarazo infantil forzado muestra la trama institucional y las estrategias para restringir derechos movilizadas por actores que movilizan interpretaciones estratégicas del "Interés Superior", la definición de "niño" y la CDN. Estas tramas institucionales no son novedosas. De hecho, los conflictos de competencias entre los organismos de aplicación de la ley de protección dependientes del ejecutivo y el poder judicial configuraron el escenario nacional desde que se comenzara a debatir el tipo de reformas necesarias para la implementación del enfoque de derechos.

Muchas investigaciones han mostrado cómo la protección a la niñez se da en Argentina, en un campo institucional en el que densas tramas de relaciones entre actores concretos tienen predominancia en el establecimiento de las matrices de interpretación de los problemas y las rutinas de intervención que de ellas derivan. Así, la articulación entre el sistema de salud y el poder judicial para el establecimiento de urgencias o su denegación tiene en numerosas provincias aún más peso que las interpretaciones e intervenciones del Sistema de Protección de Derechos (LLOBET; VILLALTA, 201 1; VILLALTA; LLOBET, 2014; MAGISTRIS, 2012; GRINBERG, 2010). En el caso de la niña de 12 años violada por la pareja de su abuela en Tucumán, a la que se negó el acceso a la Interrupción Legal del Embarazo, convergieron la Fiscalía, el Ministerio de Salud, la Dirección del Hospital y el Obispado de Tucumán (Mariana CARBAJAL, 2019) haciendo interpretaciones de la jurisprudencia que redefinen el propio principio del individuo como base de los derechos.

En los últimos años y en el marco de conflicto sobre los derechos sexuales y reproductivos, numerosas Defensorías han interpuesto medidas de protección de los derechos del niño por nacer como "interés superior" a ser protegido, determinando al mismo tiempo que las niñas dejan de tener un "interés superior", en tanto pasan a ser tratadas como "madres", forzando así la declaración interpretativa relativa al artículo 1. Para justificar su accionar, los actores institucionales se amparan en una comprensión de "niño" que excluye a la niña gestante. El efecto de la sexualización sobre los sentidos sociales de infancia es de larga data. Las muchachas internadas en hospicios o encarceladas desde inicios del siglo XX lo eran fundamentalmente por su comportamiento sexual (GUY, 2011 ) o por deambular en el espacio público solas (Lila CAIMARI, 2007). Los diagnósticos de insania se derivaban en muchos casos de ausencia de "pudor" o una actividad sexual que era considerada inapropiada para la edad, el sector social o la raza (Ann STOLER, 2002). En el contexto contemporáneo, la sexualización, incluso si forzada, revierte en una restricción de la infancia, en tanto se movilizan aún sentidos y sensibilidades morales vinculadas a la inocencia infantil.

De hecho, estas sensibilidades frente a la sexualización de las niñas son explotadas por actores de la sociedad civil que movilizan, ante los casos de embarazos producto de la violación, la idea de "víctima inocente": el producto de la violación no es "culpable", y se preguntan "¿por qué el bebé inocente es sentenciado a muerte?". El uso selectivo de la inocencia implica que, si bien no necesariamente se señala a la niña como "culpable" de la violación, a partir de su "actividad sexual" su propio carácter infantil y los derechos de él derivados quedan suspendidos.

A la vez, releen el estatuto del embrión como un individuo autónomo, a despecho de su dependencia absoluta del cuerpo de la gestante. En tal sentido, los argumentos omiten considerar la autonomía progresiva, la progresividad de los derechos, y el potencial conflicto entre los derechos de las niñas gestantes y los eventuales del feto, derivado del marco interpretativo establecido por la Conferencia de Viena en 1993 y en el carácter no absoluto y progresivo de los derechos humanos.

Al contrario, los argumentos movilizados por los sectores opuestos a la legalización del aborto avanzan en retomar los argumentos críticos contra la CDN en virtud de su "occidentalocentrismo nórdico" a la vez que recuperan las críticas feministas tercermundistas contra las políiticas que, en

\footnotetext{
${ }^{4}$ Se define que "embarazo infantil forzado" es el que ocurre "cuando una niña (menor de 14) queda embarazada sin haberlo buscado o deseado y se le niega, dificulta, demora u obstaculiza la interrupción del embarazo". El embarazo puede ser producto de una violación o provenir de una relación sexual consensuada, en la que la niña no conocía las consecuencias o conociéndolas, no pudo prevenirlas.
} 
pos de aumentar derechos individuales de las mujeres, construían la sexualidad "nativa" como problemática. Reclamos de soberanía nacional y declaraciones contra el "imperialismo de la ONU" conviven con los usos estratégicos de los principios de la CDN que hemos descripto. Por su parte, se trata de actores que no están presentes sólo al momento de debatir públicamente estas cuestiones. Muy por el contrario, organizaciones vinculadas con los movimientos neo-pentecostales y católicos brindan servicios territoriales sustantivos para la implementación del sistema de protección de derechos en articulación con los organismos estatales, tanto en materia de prestaciones para adolescentes comprometidos con consumos problemáticos como en materia de acogimiento en medio familiar alternativo. Así, son actores con incidencia concreta en el desarrollo de la protección integral. Por su lado, las organizaciones de mujeres, los colectivos feministas, y las propias agencias estatales vinculadas con los derechos de las niñas y las mujeres son raramente incluidas en la gestión de la protección, incluso cuando en distritos como la provincia de Buenos Aires, alrededor del $70 \%$ de los casos administrados se vinculan con violencia doméstica y de género (LLOBET, 2018).

Este desarrollo sirve para ahondar en dos cuestiones. Por un lado, que los derechos son objeto de disputa y sus interpretaciones son histórica y estratégicamente situadas. Por otro, leyes y derechos se concretan en prácticas sociales, de modo que no preceden, desde el punto de vista sociohistórico, a su efectivización. Así, los actores institucionales que intervienen movilizando interpretaciones estratégicas, las tramas de relaciones y articulaciones que conducen a posibilitar que determinados actores ganen coyunturalmente "poder de fuego", las políticas -sanitarias, educativas, etc.- y la voluntad expresada en sus posibilidades de implementación, resultan determinantes para entender los modos en que se concreta la protección de derechos.

\section{A modo de conclusión}

La infancia y los niños han estado ausentes de las conceptualizaciones feministas sobre las regulaciones de género (Barry THORNE, 1987; Erica BURMAN; Jackie STACEY, 2010), a pesar de que la infantilización de las mujeres, esto es, su tratamiento como sujetos incapaces o requeridos de tutela, ha sido paralela a la "feminización de la infancia" como un estado de dependencia (BURMAN, 2008), a la vez que como tema y problema "propio" de las mujeres, y a pesar del valor político ambivalente de las relaciones materno-filiales.

La revisión del proceso histórico de producción de oposiciones variables entre los derechos e intereses de las mujeres y los de niños/as supone desafiar el carácter supuestamente "nogenerizado" y muchas veces expresamente anti-feminista del paradigma de los derechos de los niños. A la vez, invita a ponderar el uso estratégico de la polivalencia simbólica de los derechos, cuya variación depende de los actores y sus coyunturas histórico-políticas de actuación, que tanto permitieron mejorar las posibilidades de actuación política legítima de las mujeres como se movilizan para limitar libertades y autonomía sobre el propio cuerpo. Finalmente, permiten considerar que los logros de los derechos de las mujeres dependen de la articulación contradictoria y frágil entre principios liberales y aspiraciones de igualdad.

No es de despreciar la sospecha con que las organizaciones de mujeres miraron tempranamente a la CDN. En el contexto actual, es precisamente aquello que las feministas señalaron como peligroso lo que mostró su ductilidad para constituirse en un problema para nuestros derechos.

\section{Referencias}

BARNA, Agustín. "Convención Internacional de los Derechos del Niño. Hacia un abordaje desacralizador". Revista Kayros, San Luis, 2012.

BBC. "No es natural", "pone en riesgo a los niños", "la familia debe ser como Jesús, María y José": las razones por las que miles se oponen al matrimonio igualitario en México. Disponible en https://www. bbc.com/mundo/noticias-america-latina-37467052. Consultado el 23/01/2019.

BELOFF, Mary. "Fortalezas y debilidades del litigio estratégico para el fortalecimiento de los estándares internacionales y regionales de protección a la niñez en América Latina". 2008. [online]. Observatorio de Jóvenes, UBA, Buenos Aires. Disponible en http://www.observatoriojovenes.com.ar/almacen/file/ Fortalezas\%20y\%20debilidades_\%20 Mary\%20Beloff.pdf. Consultado el: 23/01/2019

BURMAN, Erica; STACEY Jackie. "The Child and Childhood in Feminist Theory". Feminist Theory, v. 11 , p. 227, 2010.

BURMAN, Erica. "Innocents abroad: Western fantasies of childhood and the iconography of emergencies". Disasters, v. 18, n. 3, p. 238-253, 1996b.

BURMAN, Erica. "Local, Global or Globalized?: Child Development and International Child Rights Legislation". Childhood, Londres, v. 3, p.45-66, 1996a. 
BURMAN, Erica. “Beyond 'Women Vs. Children' or 'Women and Children': Engendering Childhood and Reformulating Motherhood". International Journal of Children's Rights, v. 16, p. 177-194, 2008.

CAIMARI, Lila. "Entre la Celda y el Hogar Dilemas Estatales del Castigo Femenino (Buenos Aires, 1890-1940)". Nueva Doctrina Penal, p. 427-450, 2007.

CARBAJAL, Mariana. "La trama urdida para dilatar la violación de la niña tucumana". 2019. Página 12. Disponible en https://www.pagina12.com.ar/177619-la-trama-urdida-para-dilatar-laviolacion-de-la-nina-tucuman. Consultado el 28/02/2019.

CECHI, Horacio. Entrevista a Vilma Ibarra. El matrimonio gay es debate parlamentario. 2009. Página 12. Disponible en https://www.pagina12.com.ar/diario/sociedad/3-134183-2009-10-27.html. Consultado el 23/01/2019.

CHENEY, Kristen. "Global Rights Discourse, National Developments, and Local Childhoods: Dilemmas of Childhood and Nationhood in Uganda, East Africa". Histoires d'enfant, histoires d'enfance, Tome I: Civilisation. Tours: Presses Universitaires Franc'ois Rabelais, 2007.

COMISIÓN INTERAMERICANA DE DERECHOS HUMANOS (CIDH). CASO 12.502 ATALA RIFFO E HIJAS VS. CHILE. Observaciones finales escritas. 24/09/2011. Disponible en http://www.corteidh.or.cr/docs/ casos/atala/alefcom.pdf . Consultado el 23/01/2019.

DE PAZ TRUEBA, Yolanda. "La participación de las mujeres en la construcción del Estado social en la Argentina. El centro y sur bonaerenses a fines del siglo XIX y principios del XX". Anuario del Centro de Estudios Históricos "Prof. Carlos S. A. Segreti”, Córdoba, Argentina, a. 9, n. 9, p. 117-134, 2009.

DIARIO LA NACIÓN. "Sigue la controversia por el matrimonio gay y crece la expectativa por la votación en el senado". La Nación, 5/5/2010. Disponible en https://www.lanacion.com.ar/1261381-sigue-lacontroversia-por-el-matrimonio-gay-y-crece-la-expectativa-por-la-votacion-en-el-senado. Consultado el 23/01/2019.

DONZELOT, Jacques. A poliìcia das famiilias. Rio de Janeiro: Graal, 1980.

ERASO, Yolanda (Ed.). Mujeres y asistencia social en Latinoamérica, siglos XIX y XX: Argentina, Colombia, Meixico, Peruì y Uruguay. Coìrdoba: Alción, 2009.

FASSIN, Didier. "A contribution to the critique of moral reason". Anthropological Theory, v. 1 1, n. 4, p. 481-491, 2011.

FONSECA, Claudia. "As novas tecnologias legais na produção da vida familiar. Antropologia direito e subjetividades". Civitas, Porto Alegre, v. 11, n. 1, p. 8-23, jan.-abr. 2011.

FONSECA, Claudia. "Inequality Near and Far: Adoption as Seen from The Brazilian Favelas". Law \& Society Review. v. 36, n. 2, p. 101-134, 2002.

FONSECA, Claudia; CARDARELLO, Andrea. "Derechos de los más y menos humanos". In: TISCORNIA, Sofiìa; PITA, María (eds.). Derechos humanos, tribunales y policiìas en Argentina y Brasil. Estudios de antropología jurídica. Buenos Aires: Antropofagia. p. 9-41, 2005.

FONSECA, Claudia. "Os direitos da criança. Dialogando com o ECA". In: FONSECA, Claudia; TERTO, Veriano; FARIAS ALVES, Caleb (Orgs.). Antropologia, diversidade e direitos humanos. Diálogos interdisciplinares, Porto Alegre: UFRGS Editora, 2004.

FOUCAULT, Michel. "The Subject and the Power". In: DREYFUS, Hubert (Ed.). Michel Foucault, Beyond structuralism and hermeneutics. Chicago: University of Chicago Press, 1983.

GONZAilLEZ DE LA VEGA, Geraldina. "El interés superior del niño y la orientación sexual. Dos casos y una propuesta". Revista derecho en libertad, Facultad Libre de Derecho de Monterrey, Monterrey, n. 6, p. 82-123, julio-diciembre 2011.

GORDON, Linda. "The Perils of Innocence, or What's Wrong with Putting Children First". Journal of The History of Childhood and Youth, v. 1, n. 3, p. 331-350, 2008.

GRINBERG, Julieta. "La Recepción de "Los Derechos Del Niño" en Argentina: Trayectorias de Activistas y Conformación de una Nueva Causa en Torno a la Infancia". Virajes antropología sociología, v. 15, n. 1, p. 299-325, enero- junio, 2013. 
GRINBERG, Julieta. "De "malos tratos", "abusos sexuales" y "negligencias". Reflexiones en torno al tratamiento estatal de las violencias hacia los niños en la ciudad de Buenos Aires". In: VILLALTA, Carla (Comp.). Infancia, justicia y derechos humanos. Bernal: Universidad Nacional de Quilmes, 2010. p. 73-108.

GUY, Donna. "Niños Abandonados En Buenos Aires (1880-1914) Y El Desarrollo Del Concepto De La Madre". In: FLETCHER, Lea (Comp.). Mujeres y Cultura en la Argentina del Siglo XIX. Buenos Aires: Feminaria Editora, 1994.

GUY, Donna. "The Politics of Pan-American Cooperation: Maternalist Feminism and the Child Rights Movement, 1913-1960". Gender \& History, v. 10, n. 3, p. 449-469, Nov. 1998.

GUY, Donna. Las Mujeres Y La Construcción del Estado de Bienestar. Caridad y Creación de Derechos en Argentina. Buenos Aires: Prometeo Libros, 2011.

HART, Roger. Children's Participation. New York: UNICEF, 1997.

JELIN, Elizabeth. "Los derechos como resultado de luchas históricas". In: JELIN, Elizabeth; CAGGIANO, Sergio; MOMBELLO, Laura. Por los derechos. Hombres y mujeres en la acción colectiva. Buenos Aires: Editorial Nueva Trilce, 2011.

LENOIR, Rémi. "La famille, une affaire d’État. Les débats parlementaires concernant la famille (19731978)." Actes de la recherche en Sciences Sociales, v. 113, p. 16-30, juin 1996.

LLOBET, Valeria; VILLALTA, Carla. Estado de Situación del Sistema de Protección Integral de Derechos, Provincias de Mendoza y San Juan. Buenos Aires: UBA-SENNAF, 2011.

LLOBET, Valeria. ¿Fábricas de Niños? Las instituciones en la era de los derechos. Buenos Aires: Editorial Novedades Educativas, 2009.

MILANICH, Nara. "Los Hijos de la Providencia: el Abandono como Circulación en el Chile Decimonónico". Revista de Historia Social y de las Mentalidades, n. 5, p. 79-100, invierno 2001.

MORENO, José Luis. Historia de la Familia en el Río de la Plata. Buenos Aires: Editorial Sudamericana, 2004.

MOREYRA, Beatriz. Cuestión social y políticas sociales en la Argentina. La modernidad periférica. Córdoba, 1900-1930. Bernal: Universidad Nacional de Quilmes, 2009.

NARI, Marcela. "Maternidad, Poliitica y Feminismo". In: GIL LOZANO, Fernanda; PITA, Valeria; INI, María Gabriela. Historia de las Mujeres Argentinas Siglo XX. Buenos Aires: Taurus, 2000.

PAVEZ, Iskra. "Sociología de la Infancia y derechos: Las Niñas y los Niños como Actores Sociales". Revista Señales, a. 5, n. 10 p. 40-55, 2012.

PILOTI, Francisco. "The historical development of the child welfare system in Latin America. An overview". Childhood, v. 6, n. 4, p. 408-422, 1999.

PITA, Valeria. "Política, Conflictos y Consensos en Torno al Brazo Asistencial del Estado. Buenos Aires, 1880-1910". In: ERASO, Yolanda (Comp.). Mujeres y Asistencia Social en Latinoamérica, siglos XIX y XX. Argentina, Colombia, México, Perú y Uruguay. Córdoba: Alción, 2009. p. 95-130.

PRICE COHEN, Cynthia. "The United Nations Convention of the Rights of the Child: A Feminist Landmark". William \& Mary Journal of Women and the Law [online], Williamsburg, v. 13, n. 1, 1997. Disponible en http://scholarship.law.wm.edu/wmjowl/vol3/iss1/3. ISSN 1081-549X.

PUPAVAC, Vanessa. "A Critical Review of Children's Rights in Context". School of Politics University of Nottingham, UK, 2001.

REYNAERT, Didier; BOUVERNE-DE BIE, Maria; VANDEVELDE, Stijn. "A review of children's rights literature since the adoption of the United Nations Convention on the Rights of the Child". Childhood, v. 1, n. 4, p. 518-534. London: Sage Publications, 2009.

REYNOLDS, Pamela; NIEUWENHUYS, Olga; HANSON, Karl. "Refractions of Children's Rights in development practice. A view from anthropology". Childhood, v. 13 n. 3, p. 291-302, 2006.

SANTILLÁN, Laura. "El cuidado infantil, la vida familiar y las formas en que se territorializan las intervenciones sociales: un estudio en barrios populares del Gran Buenos Aires". In: COSSE, Isabella; 
LLOBET, Valeria; VILLALTA, Carla; ZAPIOLA, María Carolina (Eds.). Infancias: poliiticas y saberes en Argentina y Brasil (siglos XIX y XX). Buenos Aires: Teseo, 2011.

SCHEINVAR, Estela. Derechos, ¿para qué humanos? Control biopolítico y prácticas de derechos humanos. In: II CONGRESO LATINOAMERICANO Y CARIBEÑO DE CIENCIAS SOCIALES, 2, 2010, MÉXICO, FLACSO. Anales... Disponible en http://www.infancia-juventude.uerj.br/pdf/estela/derechosparaque humanos.pdf.

SCHUCH, Patrice. "Como a Família Funciona em Políticas de Intervenção Social?". Civitas, v. 13, n. 2, p. 309-325, maio-ago. 2013.

SCHUCH, Patrice. Práticas de Justiça. Antropologia dos Modos de Governo da Infância e Juventude no Contexto Pós-ECA. Porto Alegre: Editora UFRGS, 2009.

STOLER, Ann. Carnal Knowledge and Imperial Power: Race and the Intimate in Colonial Rule. Berkeley: University of California Press, 2002.

SURIANO, Juan. (Comp.) La cuestión social en Argentina, 1870-1943. Buenos Aires: Ed. La Colmena, 2000.

THERBORN, Gorän. "Child Politics: Dimensions and Perspectives". Childhood, v. 3, n. 1, p. 29-44, 1996.

THÉRY, Irène. Couple, filiation et parenté aujourd'hui: Le droit face aux mutations de la famille et de la vie privée. Paris: Editions Odile Jacob, 1998.

THORNE, Barry. "Re-Envisioning Women and Social Change: Where Are the Children?". Gender \& Society, v. 1, n. 1, p. 85-109, 1987.

TOSSOUNIAN, Cecilia. "Women's Associations and the Emergence of a Social State: Protection for Mothers and Children in Buenos Aires, 1920-1940". Journal of Latin American Studies, v. 45, p. 297 $324,2013$.

VEERMAN, Philip. "Towards a More Integrated Basis for the Children's Rights Movement: The Aims and Outcome of the First International Interdisciplinary Study-Group on Ideologies of Children's Rights". In: FREEMAN, Michael; VEERMAN, Philip (Eds.). The Ideologies of Children's Rights. The Hague: Martinus Nijhoff. 1992. p. 357-63.

VERHELLEN, Eugene. Convention on the Rights of the Child. Background, Motivation, Estrategies, Main Themes. Leuve; Appeldom: Garant, 1994.

VIANNA Adriana. "Direitos, Moralidades e Desigualdades: Considerações a partir de Processos de Guarda de Crianças". In: KANT DE LIMA, Roberto. Antropologia e Direitos Humanos. Niterói: EdUFF, 2005. p. 13-68.

VILLALTA, Carla. "¿De quién son los niños pobres? El debate por la tutela administrativa, judicial o caritativa en Buenos Aires de fin de siglo pasado". In: TISCORNIA, Sofía; PITA, María Victoria. (Comps.). Derechos Humanos, Tribunales y Policía en Argentina y Brasil. Equipo de Antropología Política y Jurídica, Ffyl, UBA. Buenos Aires: Ed. Antropofagia, 2005. p. 71-88.

VILLALTA, Carla. "La conformación de una matriz interpretativa. La definición jurídica del abandono y la pérdida de la patria potestad". In: LIONETTI, Lucía; MíGUEZ, Daniel (Comps.). Las Infancias en La Historia Argentina. Intersecciones entre Prácticas, Discursos e Instituciones (1890-1960). Rosario: Ed. Prohistoria, 2010.

Valeria LLobet (vllobet@unsam.edu.ar) es doctora de la UBA (Psicología). Trabaja en temas de política y derechos humanos, desde un punto de vista que articula las desigualdades de género y la edad. Investigadora Independiente del CONICET en UNSAM. Dirige el Centro de Estudios sobre Desigualdades, Sujetos e Instituciones (CEDESI), y tiene a cargo las materias de grado Introducción a los Estudios de Género, y Derechos Humanos y Educación 


\section{COMO CITAR ESTE ARTíCULO, DE ACUERDO CON LAS NORMAS DE LA REVISTA:}

LLOBET, Valeria. "Tensiones entre derechos de las mujeres y protección de la niñez". Revista Estudos Feministas, Florianópolis, v. 28, n. 3, e65412, 2020.

\section{CONTRIBUCIÓN DE AUTORÍA}

No se aplica.

\section{FINANCIACIÓN}

No se aplica.

\section{CONSENTIMIENTO DE USO DE IMAGEN}

No se aplica.

\section{APROBACIÓN DE COMITÉ DE ÉTICA EN INVESTIGACIÓN}

No se aplica.

\section{CONFLICTO DE INTERESES}

No se aplica.

\section{LICENCIA DE USO}

Este artículo está licenciado bajo la Licencia Creative Commons CC-BY Internacional. Con esta licencia se puede compartir, adaptar, crear material para cualquier objetivo, siempre que se le atribuya la autoría.

\section{HISTORIAL}

Recibido el 01/04/2019

Presentado nuevamente el 30/08/2019

Aprobado el 05/11/2019 